\title{
Oficina de florestas: \\ Tupi or not Tupi, that is the question
}

Forest workshop:

Tupi or not Tupi, that is the question

\section{Luiz Davi Vieira Gonçalves}

Luiz Davi Vieira Gonçalves

Doutor em Antropologia Social pela Universidade Federal do

Amazonas (Ufam), Professor Adjunto do Curso de Teatro da Universidade do Estado do Amazonas (UEA), líder do diretório de pesquisa

TABIHUNI/CNPq/UEA e pesquisador do Instituto Nacional de Ciência e Tecnologia Brasil Plural (INCT-BP), em Manaus.

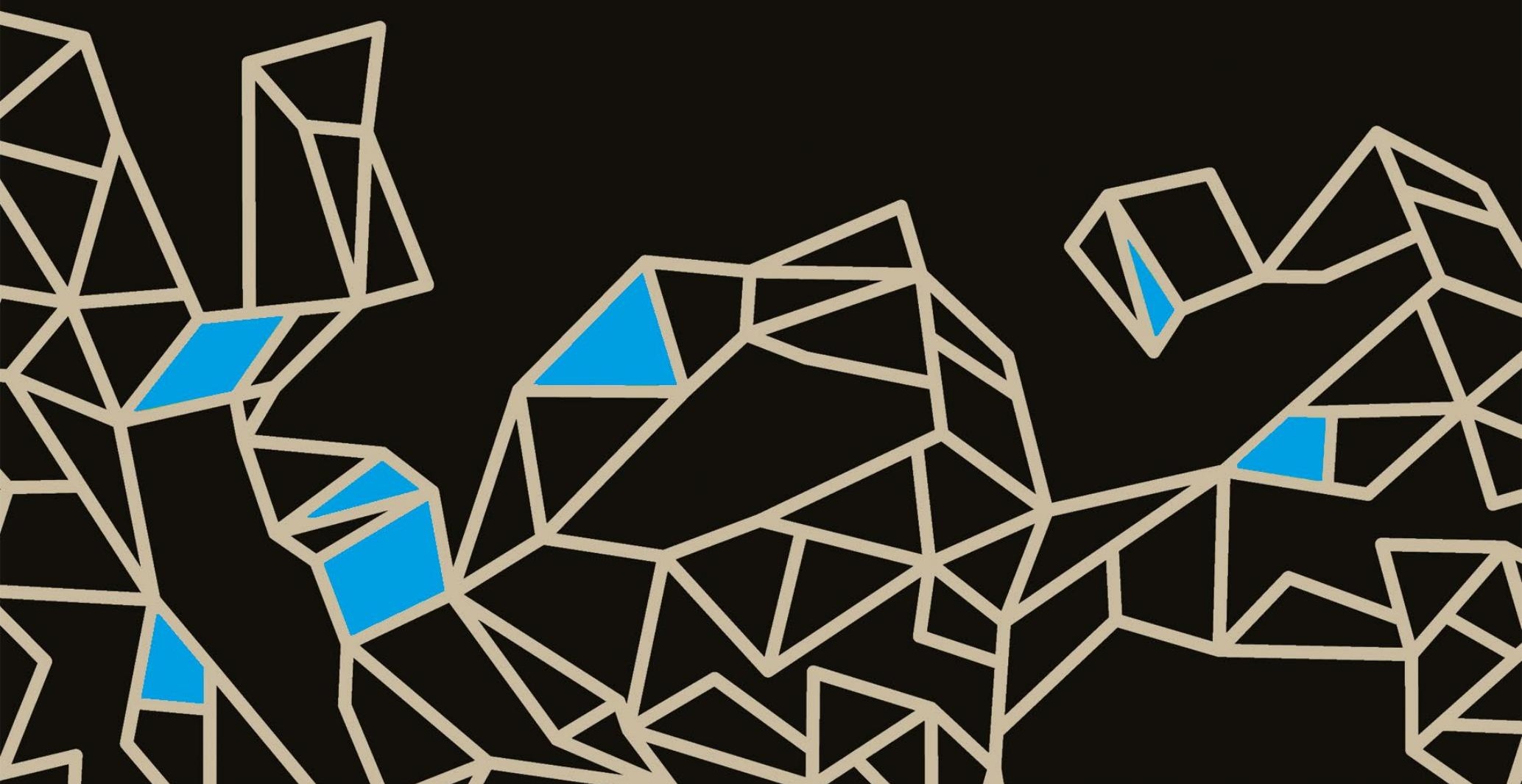




\section{Resumo}

Este artigo apresenta uma reflexão acerca da dimensão do teatro e os povos indígenas. Com um olhar expandido sobre a cena teatral brasileira, traz os trabalhos desenvolvidos pelo grupo de pesquisa Tabihuni, da cidade de Manaus, e pela companhia de teatro Oficina Uzyna Uzona, da cidade de São Paulo. O primeiro destaca-se pela participação direta dos indígenas nas performances Uwanary tendawa e Ühpü; o segundo, pela presença cênica vital dos envolvidos, elenco e público, no espetáculo Os sertões.

Palavras-chave: Teatro, Povos indígenas, Tabihuni, Teatro Oficina.

\section{Abstract}

This article reflects on the dimension of theater and the indigenous peoples. With an expanded look at the Brazilian theatrical scene, this paper show the studies developed by the research group Tabihuni in the municipality of Manaus, state of Amazonas, and by the company theater: Teatro Oficina Uzyna Uzona from São Paulo. The first stands out due to the direct participation of the indigenous people in the performances Uwanary tendawa and Ühpü and, the second, due to the vital scenic presence, cast and audience of those involved, in the play Os Sertões.

Keywords: Theater, Indigenous people, Tabihuni, Teatro Oficina.

Escrever sobre os povos indígenas deste lugar chamado Brasil, pensando sua relação com o campo das Artes da Cena (aqui especificamente a partir dos grupos Tabihuni e Teatro Oficina) é, sobretudo, um grande desafio para qualquer pesquisador(a) por se tratar, de acordo com a Fundação Nacional do Índio (Funai), de uma diversidade composta por 305 etnias e 274 línguas faladas. Ao olharmos para a realidade desses povos de forma impoluta, esse desafio fica ainda mais laborioso quando percebemos os conhecimentos tradicionais travando uma luta ininterrupta por sobrevivência diante de um cenário de extermínio étnico em nosso país.

Trabalhar com os povos indígenas diante da realidade conflituosa que está posta mudou minha vida (GONÇALVES, 2018). De 2013 (momento em que fui morar na Amazônia) até hoje, atuo diretamente com os Yanomami do 
xapono (aldeia) Maturacá, subgrupo dos Yanomami, e com os Ye'pa Masha (Tukano), no contexto urbano de Manaus, que conta com uma diversidade de alunos(as) de vários grupos étnicos existentes na Universidade do Estado do Amazonas (UEA) e na Universidade Federal do Amazonas (Ufam) - nas quais atuo como professor e pesquisador no campo do Teatro e da Antropologia. A experiência fez com que eu sofresse uma transformação como ser humano: um artista que se tornou antropólogo, que depois se (re)conheceu como artista e, em seguida, no exercício kõkamõu, que na língua Yanomami falada na região de Maturacá, Alto Rio Negro, significa "estar juntos(as)", aprendeu a ser artista-antropólogo.

O significado da palavra kõkamõu dá sentido à minha relação construída com os povos indígenas. Por meio delas fui aprendendo, ao longo dos anos, a reconhecer e deixar-me afetar pelo estado de presença dos indígenas, carregado de muito afeto, resistência e desejo pela vida. Durante o exercício, pude perceber, na experiência com as performances tradicionais especialmente com o xamanismo -, que o conhecimento se dá pela prática em diversas atividades no dia a dia. Mesmo aquelas que, às vezes, não estão ligadas ao objetivo central, conduzem ao entendimento central cosmológico (GONÇALVES, 2019), por exemplo: aprendi muito sobre xamanismo jogando futebol na aldeia, colhendo frutas na floresta, pescando e, muitas vezes, falando de assuntos aleatórios como sexo, vida na cidade e tantos outros. O ser e o estar são verdadeiros em todos os momentos de nossa existência.

Assim, pautado pela vivência na Amazônia indígena e pela formação acadêmica, passei a chamar essa forma verdadeira e simétrica de ser e estar no mundo de metodologia Kõkamõu; sobretudo, proponho aos interessados(as), predominantemente do campo das artes da cena, um olhar afetivo, profundo $e$ responsável aos povos tradicionais, de forma que sejam levados em consideração os desejos dos próprios nativos e também os afetos estabelecidos dentro de uma pesquisa acadêmica - frequentemente desenvolvida de forma distanciada, rígida e engessada (GONÇALVES, 2020). Sempre questiono em meus alfarrábios, palestras, espetáculos teatrais e aulas, se nós, artistas, estamos realmente dispostos à relação simétrica com os povos indígenas, assimilando todas as demandas reais que deles sobressaem, ou apenas queremos extrair técnicas corporais e conhecimentos tradicionais travestidos de positividade. 
Assim, trouxe para o subtítulo deste artigo a famosa expressão do poeta Oswald de Andrade, publicada em seu manifesto antropófago "Tupi or not tupi: that is the question", como proposta de reflexão para pensarmos até quando iremos menosprezar a realidade instaurada no âmago de nosso "BraZil"? Todavia, sem maiores preâmbulos sobre essa problemática e indo ao ponto central aqui proposto, apresento uma questão ainda mais específica: por que nós, artistas e arte-educadores, temos tanta dificuldade de mergulhar no estado de presença impoluta dos rituais dos povos tradicionais e ainda mantemos a grande maioria de nossas "produções" voltadas para métodos e práticas vindas de fora?

A partir da questão lançada, adoto como escopo central um olhar expandido sobre a cena teatral brasileira, apresentando o trabalho desenvolvido pelo grupo de pesquisa Tabihuni, da cidade de Manaus - do qual sou coordenador -, e pela companhia Teatro Oficina Uzyna Uzona, da cidade de São Paulo, coordenada por José Celso Martinez Corrêa. O objetivo dessa abordagem é mostrar o estado de presença dos envolvidos nas encenações de ambos os grupos: o primeiro destaca-se pela participação direta dos indígenas nas performances Uwanary tendawa e Ühpü; o segundo, pelo jogo da presença cênica dos envolvidos no espetáculo Os sertões.

O Tabihuni - Núcleo de Pesquisa e Experimentações das Teatralidades Contemporâneas e suas interfaces Pedagógicas CNPq/UEA -, radicado na Universidade do Estado do Amazonas, atua desde 2014 com montagens cênicas, publicações de artigos e livros, realização de eventos artísticos e acadêmicos junto aos povos indígenas da Amazônia brasileira. O objetivo aqui é investigar o corpo plural da Amazônia e suas interfaces pedagógicas, buscando, sobretudo, uma relação simétrica com os povos tradicionais e o encontro com a arte decolonial. Destacam-se duas performances durante o período desta pesquisa: Uwanary tendawa e Ühpü.

A performance Uwanary tendawa, que significa "força de guerreiro" na língua karapãna, foi a primeira montagem do grupo Tabihuni com indígenas em cena. Essa proposta de trabalhar diretamente com os indígenas nasce diante da preocupação do grupo em abraçar as demandas advindas das necessidades reais dos próprios indígenas - dessa forma, nos diálogos com os movimentos e reuniões sobre demarcações de terra, surge a proposta de 
criação do Uwanary tendawa, peça que narra as várias desapropriações sofridas pelos indígenas decorrentes da especulação imobiliária. A montagem conta com a participação de indígenas de diversas etnias, moradores da aldeia Parque das Tribos, situada região urbana da cidade de Manaus que já dispõe de um histórico de desapropriações.

Estávamos montando o espetáculo Uwanary tendawa (Figura 1) quando propus: "chegou o momento do trabalho em que montarão as cenas de acordo com a cultura de vocês." Não demorou muito, eles começaram a brigar entre si, porque uma indígena da etnia Witoto dizia: "a gente vai dançar assim essa música", e os Tikunas retrucavam: "não, porque não dançamos assim". Do outro lado, os Karapãnas ficavam observando e comentavam entre eles: "eles acham que sabem dançar melhor do que a gente porque falam a língua", enquanto eu pensava: "são noções de corpo completamente diferentes uma da outra. Talvez, se não fosse a cidade, esses corpos jamais se encontrariam para dançar juntos." Por conseguinte, chegamos à conclusão de que o formato de montagem cênica padrão que aprendemos nas escolas de teatro não servia para trabalhar com os povos indígenas - marcações, textos decorados, movimentos preestabelecidos, representação, roteiro demarcado com início, meio e fim... Esses sãodirecionamentos que escapam completamente da lógica de existência dos indígenas.

Figura 1 - Performance Uwanary tendawa

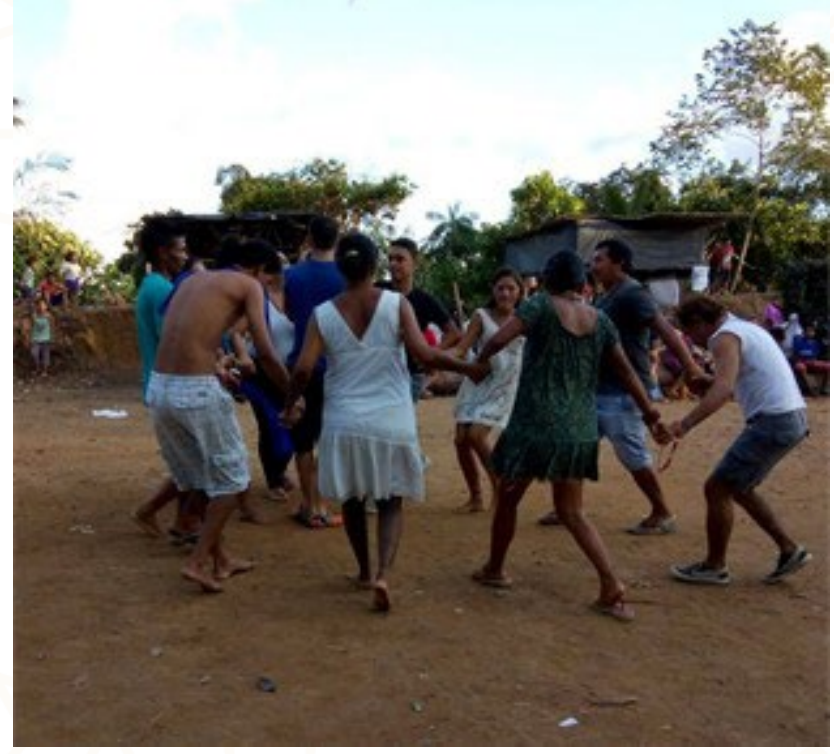

Fonte: acervo do grupo Tabihuni 
Nesse contexto, em oposição às marcações do teatro eurocentrista, o grupo de pesquisa Tabihuni está há cinco anos mergulhado nas práticas ritualísticas da Amazônia, especificamente no xamanismo Yanonami e Ye'pa Masha (Tukano), com o objetivo de encontrar o melhor caminho para uma relação simétrica e decolonial. Todavia, consideramos que caminhar kõkãmou faz-se necessário para que todas as partes estejam envolvidas diretamente no processo criativo, assumindo os afetos e suas responsabilidades. Pautados pela metodologia kõkãmou, convidamos o xamã Bu'u Kennedy da etnia Ye'pa Masha para orientar nossos processos criativos em diálogo com o xamanismo. Nascia, dessa colaboração, a performance-ritual Ühpü.

As primeiras experiências xamânicas do grupo de pesquisa Tabihuni, visando o processo de criação da performance-ritual Ühpü (Figura 2) em parceria com o kumū (xamã) Bu'u Kennedy, aconteceram nos últimos meses de 2018. Diante da afetação dos integrantes e da manutenção da performance-ritual, porém, o espetáculo vigora até os tempos atuais e vêm sendo apresentado em festivais de Teatro, encontros acadêmicos e eventos do movimento indígena. A palavra “ühpü”, segundo o Bu'u, vem da língua Ye'pa Masha, falada por sua família, e significa "corpo" - nome escolhido para a peça em virtude do estado que o corpo pode alcançar durante os rituais.

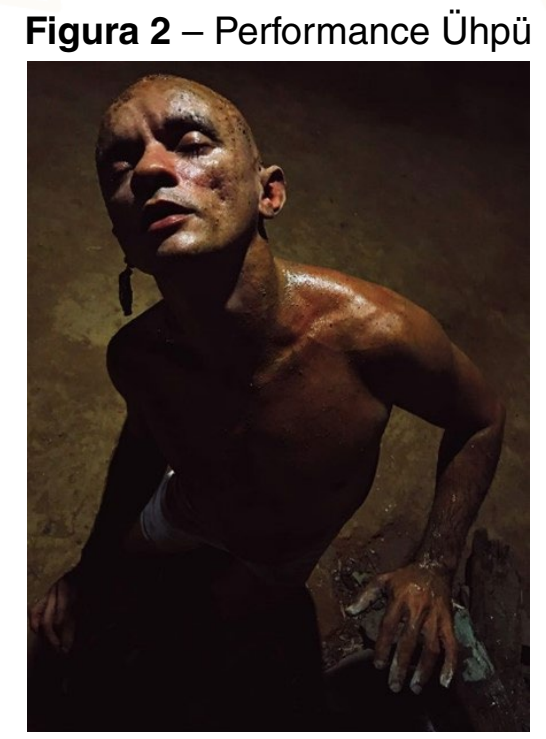

Fonte: Cesar Nogueira, grupo Tabihuni

Vale salientar que, para acessar o estado ritual do corpo, o Bu'u, desde o início, destacou a importância de mantermos as orientações de participação 
no ritual para que os objetivos do grupo e da performance-ritual fossem alcançados. Por esse motivo, tivemos duas desistências do elenco, ambas pela dificuldade de manter à risca orientações como não beber, não usar qualquer tipo de entorpecentes, não fumar, não comer alimentos fritos e assados e não praticar relações sexuais. Todas as orientações são, segundo Bu'u, para que o corpo fique preparado para os contatos energéticos estabelecidos pelos espíritos, que mantêm diálogo com o grupo durante os rituais e ficam circunscritos a ele durante longo tempo após as sessões de xamanismo.

Nessa etapa, o Bu'u sugeriu a participação do xamã Chris TK, da etnia Huni Kuin (Kaxinawa), para ajudar os não indígenas do grupo nas experiências ritualísticas conduzidas pelo uso de medicinas tradicionais - como o rapé, a ayahuasca, a sananga e, em algumas oportunidades, o paricá. Percebemos, pelas conduções dos xamãs, que o corpo ritual era guiado pelas músicas e pelos cantos em um jogo de presença orgânica de todos os envolvidos no espaço, em que cada experiência é uma performance-ritual completamente diferente, cada uma delas tonificada pelas orientações xamânicas.

O xamanismo, para o teatro, é a descolonização não só da caixa cênica eurocêntrica, mas também da forma do eu interior do artista completamente transfigurado pelas medicinas tradicionais, fazendo com que, antes de qualquer encenação, encontrássemos nossa real existência, presença e, principalmente, nossa subjetividade no/para mundo, como destaca o indígena Ailton Krenak:

Suspender o céu é ampliar o nosso horizonte; não o horizonte prospectivo, mas um existencial. É enriquecer as nossas subjetividades, que é a matéria que este tempo que nós vivemos quer consumir. Se existe uma ânsia por consumir a natureza, existe também uma por consumir subjetividades - as nossas subjetividades. Então vamos vivê-las com a liberdade que fomos capazes de inventar, não botar ela no mercado. Já que a natureza está sendo assaltada de uma maneira tão indefensável, vamos, pelo menos, ser capazes de manter nossas subjetividades, nossas visões, nossas poéticas sobre a existência. (KRENAK, 2019, p. 32-33)

Portanto, não existe fim, e sim existência(s) subjetiva(s) - poesias corporais materiais e imateriais na presença ritual. A disponibilidade combinada entre indígena e não indígena dentro do xamanismo nos colocou em estados 
emocionais que nos proporcionaram uma transmutação do corpo. Cada integrante acessou emoções íntimas que nos levaram a refletir acerca de nossa existência enquanto artistas lidando com o ritual de xamanismo.

Por outro lado, a Companhia Teatro Oficina Uzyna Uzona, fundada em 1958 por Amir Haddad, José Celso Martinez e Carlos Queiroz Telles, coordenada até hoje por José Celso, traz em sua história mais de 50 encenações que buscaram as ritualidades brasileiras, transformando as estéticas engessadas do teatro eurocentrista. Desse percurso, destacam-se os espetáculos O rei da vela, de Oswald de Andrade, e o ciclo Os sertões, de Euclides da Cunha, que trazem como marcas importantes os corpos livres e latentes em busca da ritualidade antropofágica, disponibilidades corporais e plenas entregas dos seres humanos e não humanos presentes no local.

O envolvimento dos espectadores traz para a encenação um tom de coletividade e inclusão afetiva, oferendo uma possibilidade de afetação profun$\mathrm{da}-\mathrm{o}$ ato de trazer as pessoas para dentro do jogo ritual leva os participantes a saírem de uma posição de observação estática para mergulharem nas performances, nos cantos e nas danças feitos de cheiros, objetos, movimentos e muito jogo durante horas de apresentação. O público, como em um ritual de xamanismo, torna-se um só na relação com todos os envolvidos no espaço, atingindo um estado verdadeiro de presença - uma antropofagia teatral.

Vale salientar que o entendimento do jogo de cena aqui proposto trata da relação orgânica dos envolvidos na encenação; é um estado de presença no qual se desfaz a separação entre publico e atores, palco e plateia, tornando todos um só dentro do espaço. Tudo isso acontece diante da disponibilidade corporal e entrega dos envolvidos no jogo, que deixa de ser teatral e passa a ser ritual, já que acontece uma explosão estética e afetiva dos envolvidos no espaço.

Para uma visualização mais concreta da performance do Teatro Oficina destaco os cinco espetáculos do ciclo Os sertões, dirigidos por José Celso e disponibilizados no YouTube (OS SERTÕES..., 2020). Nele, os atores entram em profundo estado ritual atingido por meio da entrega total a um estado de verdade: trata-se de contar a história de dentro da história, com uma presença tonificada pelo prazer de ser, de estar e de pertencer ao ritual instaurado na cena; ela se mostra como um diálogo ritual que sai da realidade comum para 
uma visão e uma presença em outras perspectivas, como destaca José Celso em entrevista para revista Carta Capital:

Há alguns meses, num show em benefício do Oficina, eu e Renato [Borghi] fizemos uma cena e foi maravilhoso. Tanto eu como ele lembramos de todas as músicas e cenas da peça, porque, embora meu cansaço físico atual me faça me perder na viagem da maconha - que ao mesmo tempo me cura, me ajuda, me dá vida, me traz presente -, todas as grandes montagens do Oficina depois de $O$ Rei da Vela foram feitas com alucinógenos, todas. E eu me lembro de cada uma dessas grandes viagens, me lembro de tudo, assim como Davi Kopenawa se lembra de todas as viagens dele [com a substância yäkoana], porque ele contou isso ao antropólogo francês Bruce Albert, como está registrado nesse grande livro da cultura yanomami que hoje me inspira, A queda do céu. (MARTINEZ, 2017)

Esse deslocamento é muito comum no ritual de xamanismo, como sublinha o xamã Yanomami no livro A queda do céu: palavras de um xamã yanomami (2015):

É verdade que os xapiri às vezes nos apavoram. Podem nos deixar como mortos, desabados no chão e reduzidos ao estado de fantasmas. Mas não se deve achar que nos maltratam à toa. Querem apenas enfraquecer nossa consciência, pois se ficássemos apenas vivos, como a gente comum, eles não poderiam endireitar nosso pensamento. Sem virar outro, mantendo-se vigoroso e preocupado com o que nos cerca, seria impossível ver as coisas como os espíritos as veem. (KOPENAWA YANOMAMI; ALBERT, 2015, p. 141)

Portanto, as encenações do Teatro Oficina trazem um deslocamento de realidade que agrega elementos rituais. Como diz Davi Kopenawa, a respeito do espírito dos xapiris: são a única maneira de endireitar nossos pensamentos. Esse "endireitar" pode ser uma metáfora para aprendermos a olhar para nós mesmos dentro e fora das encenações teatrais.

\section{Considerações em processo}

Em minhas experiências nos igapós, igarapés e beiradões ${ }^{1}$ da floresta Amazônica, tive a oportunidade de dançar kõkãmou com vários grupos étnicos e,

1 Expressões amazônicas que correspondem a: floresta alagada, pequeno rio e margens de rio. 
em todos eles, me deparei com expressões humanas que são desconhecidas e/ou pouco experienciadas pelo campo das artes da cena. Um exemplo bastante comum nos povos indígenas é a presença da pessoa responsável pelo riso - tanto nos rituais como nas atividades do cotidiano. Entre os Yanomami, o nome dado a essa entidade é mokoxima: uma mulher escolhida pela família para ficar responsável pelo riso dentro do xapono (aldeia). Para tanto, desde criança, ela aprende com as mokoximapë (mulheres do riso) as técnicas de fazer o xapono ficar pey toprarou (feliz em determinados rituais e reuniões do dia a dia). Nossos cursos de formação básica e acadêmica, bemcomo nossos grupos de teatro, ainda se debruçam, em sua grande maioria, somente sobre os estudos da Commedia dell'arte, do clown, do palhaço - ou seja, ainda mantemos o pensamento reducionista e os olhares para o exterior.

As questões lançadas no início do texto, questionando a dificuldade das artes da cena em agregar, em sua episteme, as pluralidades culturais e a imensidão das formas expressivas do ser humano existentes no Brasil, são respondidas pela resistência de seus "fazedores e organizadores" em aceitar que os planos do ego sejam desfeitos por realidades e verdades diferentes; é um egocentrismo que cresce torrencialmente em busca de poder, que vai em direção ao uno, ao unitário, ao solitário... completamente ao contrário do que os povos indígenas nos convidam a ser.

Transitar, brevemente, nas corporalidades dos grupos de teatro Tabihuni eTeatro Oficina demonstrou a existência de trabalhos sendo feitos que podem desconstruir a hegemonia de práticas e teorias estrangeiras radicadas nas artes no Brasil. De um lado do país, no Norte, um grupo busca romper totalmente com as marcações eurocentristas, mergulhando nas formas expressivas materiais e imateriais dos povos da floresta Amazônica; de outro lado, na região Sudeste, outro grupo marca a história teatral do Brasil oferecendo, em suas encenações, elementos de múltiplas culturas engendrados no(s) corpo(s) antropofágico(s). Todavia, a dificuldade de nosso país em aceitar a diversidade cultural é fruto, até hoje, da colonização. Em um ato que, no âmago de nossa existência, ainda nos questiona sobre quem somos e para onde queremos ir, retorno a Oswald de Andrade (2017): "Tupi or not tupi: that is the question".

O caminho talvez seja aprendermos com as oficinas das florestas a entender que o segredo (se é que há um) é saber se colocar para o diálogo 
diante da diversidade; não há o certo e o errado. Cada realidade deve ser acolhida dialogando na sua peculiaridade cultural em um caminho kôkãmou juntos(as). Assim, faz-se necessário repensar não apenas os currículos de nossas escolas como também os espetáculos de teatro, evitando que o Dia do Índio seja apenas um dia folclórico e promovendo a ciência da existência verdadeira dos povos originários e suas múltiplas representatividades.

Por fim, é de suma importância nós, professores, entendermos que o quintal de nossa casa (seja ele em São Paulo, seja ele em Manaus) é tão importante quanto Grotowski, como Viola Spolin, dentre outros. Tecer diálogos interculturais é reconhecer nossa ancestralidade aceitando os afetos materiais e imateriais das experiências sensíveis circunscritas em nossa existência.

Finalizo este texto em um dia ermo, olhando para as mensagens de WhatsApp vindas de pessoas de vários cantos da Amazônia me pedindo ajuda... pedindo para serem ouvidas... pedindo pelo direito de respirar... clamando por oxigênio... Lágrimas! Para que o céu não caia sobre nossas cabeças, recorro ao xamanismo Yanonami².

Kõkãmou!

\section{Referências bibliográficas}

ANDRADE, O. Manifesto antropófogo e outros textos. São Paulo: Companhia das Letras, 2017.

GONÇALVES, L. D. V. Eu sou um outro você: descolonizando o saber na prática da metodologia Kõkamõu. In: BRONDANI, J. A.; HADERCHPEK, R. C.; ALMEIDA, S. (org.). Práticas decoloniais nas artes da cena. São Paulo: Giostri, 2020.

GONÇALVES, L. D. V. O(s) corpo(s) Kõkamõu: a performatividade do pajé-hekura Yanomami da região de Maturacá. 2019. Tese (Doutorado em Antropologia Social) Universidade Federal do Amazonas, Manaus, 2019.

GONÇALVES, L. D. V. Estudos étnicos nas artes da cena: a metodologia kõkamõu como perspectiva simétrica para o processo de pesquisa e criação em arte. Revista Arte da Cena, Goiânia, v. 4, p. 18-41, 2018.

KRENAK, Ailton. Ideias para adiar o fim do mundo. São Paulo: Companhia das Letras, 2019.

KOPENAWA YANOMAMI, D.; ALBERT, B. A queda do céu: palavras de um xamã yanomami. São Paulo: Companhia das Letras, 2015.

2 Ver: https://bit.ly/3as81YP. 
MARTINEZ, J. C. Zé Celso, do rei da vela a bacantes. [Entrevista cedida a] Revista Carta Capital. Carta Capital, São Paulo, 12 fev. 2017. Disponível em: https://bit.ly/ 3ar6F0p. Acesso em: 2 fev. 2021.

OS SERTÕES - teatro oficina. [S. I.: s. n.], 22 abr. 2020. 9 vídeos. Publicado pelo canal Teatro Oficina Uzyna Uzona TV UZYNA. Disponível em: https://bit.ly/3cz2YIF. Acesso em: 2 fev. 2021.

Autor convidado 